\title{
Sex differences in the link between blood cobalt concentrations and insulin resistance in adults without diabetes
}

\author{
Yong Chen ${ }^{1 \dagger}$, Haobin Huang ${ }^{2 \dagger}$, Xiaowei $\mathrm{He}^{3 \dagger}$, Weiwei Duan ${ }^{4^{*}}$ and Xuming Mo ${ }^{1 *}$
}

\begin{abstract}
Background: Little is known about the effects of environmental cobalt exposure on insulin resistance (IR) in the general adult population. We investigated the association between cobalt concentration and IR.

Methods: A total of 1281 subjects aged more than 20 years with complete blood cobalt data were identified from the National Health and Nutrition Examination Survey (NHANES) 2015-2016 cycle. Blood cobalt levels were analyzed for their association with IR among all populations and subgroups by sex. Regression coefficients and 95\% confidence intervals (Cls) of blood cobalt concentrations in association with fasting glucose, insulin and homeostatic model assessment of insulin resistance (HOMA-IR) were estimated using multivariate linear regression after adjusting for age, sex, ethnicity, alcohol consumption, body mass index, education level, and household income. A multivariate generalized linear regression analysis was further carried out to explore the association between cobalt exposure and IR.

Results: A negative association between blood cobalt concentration (coefficient $=-0.125,95 \% \mathrm{Cl}-0.234,-0.015$; $P=0.026)$ and HOMA-IR in female adults in the age- and sex-adjusted model was observed. However, no associations with HOMA-IR, fasting glucose, or insulin were found in the overall population. In the generalized linear models, participants with the lowest cobalt levels had a $2.74 \%(95 \% \mathrm{Cl} 0.04 \%, 5.50 \%)$ increase in HOMA-IR ( $P$ for trend $=0.031$ ) compared with subjects with the highest cobalt levels. Restricted cubic spline regression suggested that a non-linear relationship may exist between blood cobalt and HOMA-IR.
\end{abstract}

Conclusions: These results provide epidemiological evidence that low levels of blood cobalt are negatively associated with HOMA-IR in female adults.

Keywords: Cobalt, NHANES, Insulin resistance, HOMA-IR

\footnotetext{
* Correspondence: passion@njmu.edu.cn; mohsuming15@njmu.edu.cn

${ }^{\dagger}$ Yong Chen, Haobin Huang, and Xiaowei He contributed equally to the present study and should be regarded as joint first authors.

${ }^{4}$ Department of Bioinformatics, School of Biomedical Engineering and

Informatics, Nanjing Medical University, 101 Longmian Avenue, Nanjing

211166, China

'Department of Cardiothoracic Surgery, Children's Hospital of Nanjing

Medical University, 72 Guangzhou Road, Nanjing 210008, China

Full list of author information is available at the end of the article
}

C C The Author(s). 2021 Open Access This article is licensed under a Creative Commons Attribution 4.0 International License, which permits use, sharing, adaptation, distribution and reproduction in any medium or format, as long as you give appropriate credit to the original author(s) and the source, provide a link to the Creative Commons licence, and indicate if changes were made. The images or other third party material in this article are included in the article's Creative Commons licence, unless indicated otherwise in a credit line to the material. If material is not included in the article's Creative Commons licence and your intended use is not permitted by statutory regulation or exceeds the permitted use, you will need to obtain permission directly from the copyright holder. To view a copy of this licence, visit http://creativecommons.org/licenses/by/4.0/. The Creative Commons Public Domain Dedication waiver (http://creativecommons.org/publicdomain/zero/1.0/) applies to the data made available in this article, unless otherwise stated in a credit line to the data. 


\section{Introduction}

Insulin resistance (IR) is a condition in which normal concentrations of insulin cause a smaller than expected response in blood glucose levels [1]. Individuals with IR are susceptible to type 2 diabetes [2], and IR appears to play a crucial role in the pathogenesis of several diseases, such as polycystic ovary syndrome [3], Alzheimer's disease [4], and cognitive dysfunction [5]. Although genetic predisposition [6], obesity [7], gut microbiota [8], and lifestyle [9] may evoke a disturbance in insulin sensitivity, various environmental factors also contribute to the risk of IR [10, 11]. Epidemiological studies have shown that exposure to several metals at chronic low levels was associated with a greater risk of IR [12]. However, the associations between blood cobalt (Co) and IR have not been studied.

Co is regarded as an essential trace mineral for all animals because it is the active center of a group of coenzymes, i.e., part of the B12 vitamin, which is important for human cell metabolism [13]. Generally, cobalt compounds are used as colorants in glass, ceramics, and paints; as catalysts; and as paint drying agents. Additionally, cobalt compounds are added into agricultural supplies and medicine as trace element additives. Cobalt can enter the body through the ingestion of contaminated food, respiration, skin absorption, and exposure to components of biomaterials [14]. However, it is only essential within a certain range, and a previous study has shown that normal serum values of cobalt are less than $0.5 \mu \mathrm{g} / \mathrm{L}$ [15]. However, these studies were experimental and examined only the short-term effects of excessive cobalt exposure.

In the present study, we explored the association between blood Co levels and IR using data from the National Health and Nutrition Examination Survey (NHAN ES), a nationwide survey of the general population in the USA. Moreover, subgroup analysis was performed to investigate sex differences.

\section{Methods}

\section{Study subjects}

The National Center for Health Statistics (NCHS; Centers for Disease Control and Prevention, Atlanta, GA, USA) conducted the NHANES studies. The NHANES protocols were approved by the NCHS Research Ethics Review Board, and a data user agreement was obtained from the website (https://www.cdc.gov/nchs/data access/restrictions.htm). The NHANES is a crosssectional study and contains a nationally representative sample of the non-institutionalized USA population. We selected only the data from the participants in the 20152016 NHANES for whom cobalt concentrations had been measured. The dataset included information on basic characteristics, a health questionnaire, laboratory data (i.e., blood cobalt, fasting glucose, and fasting insulin) and body measurements. All data used were retrieved from the website of the NCHS.

Populations in the NHANES over a range of 20 years were chosen to form a random subgroup for the detection of blood cobalt levels and IR. The two primary exclusion criteria included a missing fasting glucose or insulin measurement or an age less than 20 years. We also excluded women who were pregnant because they may have an abnormal physiological status that prevents accurate detection of IR. In addition, we excluded diabetic subjects because the diabetic condition would influence the IR status. The criteria for judging type 2 diabetes mellitus is as follows: (a) a fasting blood glucose level of greater than or equal to $7.0 \mathrm{mmol} / \mathrm{l}(126 \mathrm{mg} / \mathrm{dl})$; (b) a 2-h plasma glucose level equal or greater than 11.1 $\mathrm{mmol} / \mathrm{l}(200 \mathrm{mg} / \mathrm{dl})$; and (c) the self-reported use of diabetes, insulin or oral hypoglycemic agents, as well as the presence of diabetic retinopathy.

\section{Blood cobalt and IR measurement}

The method for measuring blood cobalt concentrations is described in detail elsewhere [16]. IR was estimated by serum analysis. Fasting glucose [17] and serum insulin levels were measured according to standard procedures.

\section{Covariates}

To reduce bias in our results, we adjusted a priori confounders in the regression analyses in the present study. The confounders were as follows: age, sex, ethnicity, body mass index (BMI), education level, alcohol use, and poverty income ratio (PIR). BMI was divided into three categories: < $25 \mathrm{~kg} / \mathrm{m}^{2}, 25-30 \mathrm{~kg} / \mathrm{m}^{2}$, and $>30 \mathrm{~kg} / \mathrm{m}^{2}$. Alcohol consumption was classified by determining whether alcoholic drinks had been consumed within the past year. The PIR was represented as household income by the poverty guidelines specific to the survey year, which was categorized as low $(<1)$ or high $(\geq 1)$.

\section{Statistical methods}

Continuous variables and categorical variables are expressed as means \pm standard deviations and frequencies, respectively. Because the data were skewed in nature, we transformed the blood cobalt levels to logarithmic form (Supplemental Figure 1), and blood cobalt was regarded as quartiles in further analyses. Regression coefficients (Beta) and 95\% confidence intervals (CIs) were presented to reflect the association between blood cobalt concentration and IR in the age- and sexadjusted and fully adjusted multiple variable linear regression models. Homeostatic model assessment of insulin resistance $(($ HOMA-IR $)=[($ fasting insulin $(\mu \mathrm{U} / \mathrm{ml}) *$ fasting glucose $(\mathrm{mmol} / \mathrm{l}) / 22.5])$ [18] was used to reflect the IR status. Logistic regression analyses were 
performed to investigate the association between blood cobalt concentration and IR. The cutoff point of HOMA-IR was 4.78 (the population-specific 75 th percentile of HOMA-IR), according to a previous study [19]. We performed multivariable linear models to explore the associations between interquartile ratio increases (IQ ratio $=75$ th $/ 25$ th percentiles of cobalt levels) in blood cobalt and HOMA-IR. Furthermore, we used ordinal variables as integer values to conduct the statistical tests for linear trends. The magnitudes of the above associations are the average percent difference in HOMA-IR within each IQ ratio group, which was grouped as the subjects' cobalt variables. The formula of magnitudes was [(IQ ratio^Beta) -1$] * 100$. Restricted cubic spline regression models were performed to investigate the nonlinear relationship between blood $\mathrm{Co}$ and HOMA-IR. We used SPSS version 20.0 (SPSS, Inc., Chicago, IL) to analyze all data. All two-sided $P$ values < 0.05 were considered to indicate statistical significance.

\section{Results}

The final investigation sample consisted of 1281 adults (720 males and 561 females) from this subgroup (Fig. 1). Table 1 shows that blood cobalt levels were significantly decreased among subjects who were less than 60 years old, were male, and consumed alcohol. The means \pm standard deviations of HOMA-IR, fasting glucose, and insulin are listed in Supplemental Table 1 and classified by quartile of cobalt.

The logistic regression results showed that cobalt concentration was not significantly associated with the risk of IR, regardless of whether the ageand sex-adjusted model or fully adjusted model was used (Supplemental Table 2). The linear regression results suggested that blood the cobalt concentration was negatively associated with the HOMA-IR index in females in age- and sexadjusted models; however, the association moved substantially towards the null in the fully adjusted model (Table 2).

Table 3 indicates that blood cobalt concentrations in the lowest quartile compared with the highest quartile were positively associated with higher HOMA-IR (coefficient $=0.073,95 \% \mathrm{CI} 0.007,0.139$ for individuals under aged 60; coefficient $=0.062,95 \%$ CI 0.001 , 0.123 for females), with evidence of a dose-response relationship ( $P$ for trend $=0.016$ and 0.037). Additionally, an association with blood cobalt concentration existed in the PIR $\geq 1$ subgroup. Similarly, participants in the lowest cobalt quartile had a mean HOMA-IR that was $2.74 \%$ greater (95\% CI $0.04 \%$, $5.50 \%)$ than that in the highest quartile in females

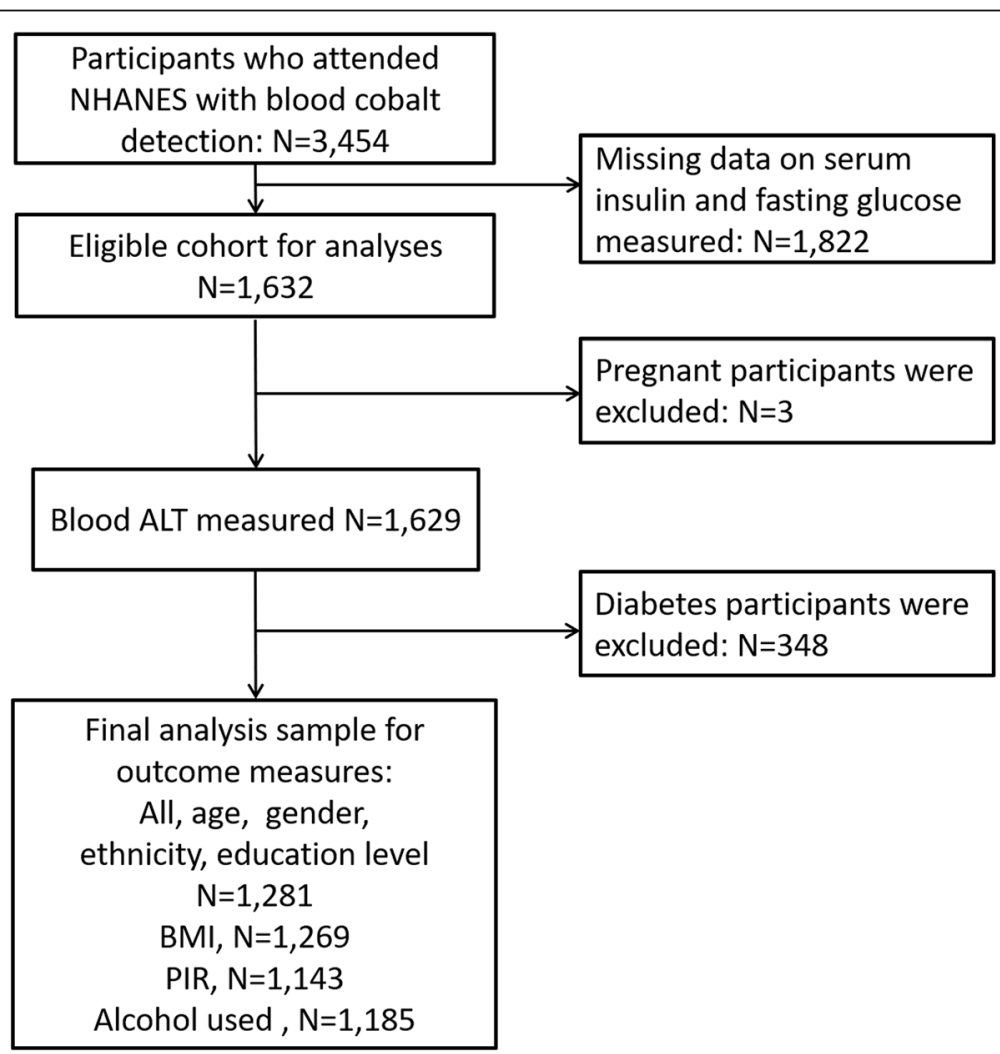

Fig. 1 Eligible participants and those included in the analyses of the associations between blood cobalt exposure and insulin resistance in adults 
Table 1 Blood cobalt concentration (mean \pm SD) according to demographics and lifestyle

\begin{tabular}{|c|c|c|c|}
\hline & \multicolumn{2}{|l|}{ Cobalt $(\mu \mathrm{g} / \mathrm{L})$} & \multirow[b]{2}{*}{$P$ value } \\
\hline & Participants [n (\%)] & Mean \pm SD & \\
\hline Overall & $1281(100 \%)$ & $0.20 \pm 0.51$ & \\
\hline Age (years) & & & $<0.001$ \\
\hline$<60$ & $720(56.2 \%)$ & $0.19 \pm 0.57$ & \\
\hline$\geq 60$ & $561(43.8 \%)$ & $0.21 \pm 0.40$ & \\
\hline Gender & & & $<0.001$ \\
\hline Male & $602(47.0 \%)$ & $0.18 \pm 0.38$ & \\
\hline Female & $679(53.0 \%)$ & $0.22 \pm 0.60$ & \\
\hline Race & & & 0.696 \\
\hline Mexican American & $180(14.1 \%)$ & $0.26 \pm 1.10$ & \\
\hline Other Hispanic & $180(14.1 \%)$ & $0.16 \pm 0.13$ & \\
\hline Non-Hispanic White & $503(39.3 \%)$ & $0.20 \pm 0.42$ & \\
\hline Non-Hispanic Black & $261(20.4 \%)$ & $0.17 \pm 0.13$ & \\
\hline Other race-including multiracial & $157(12.3 \%)$ & $0.20 \pm 0.27$ & \\
\hline $\mathrm{BMI}\left(\mathrm{kg} / \mathrm{m}^{2}\right)$ & & & 0.061 \\
\hline$<25$ & $345(26.9 \%)$ & $0.18 \pm 0.30$ & \\
\hline $25-30$ & $436(34.0 \%)$ & $0.23 \pm 0.73$ & \\
\hline$>30$ & $488(38.1 \%)$ & $0.19 \pm 0.35$ & \\
\hline Alcohol use & & & 0.001 \\
\hline Yes & $800(62.5 \%)$ & $0.19 \pm 0.34$ & \\
\hline No & 385 (30.1\%) & $0.22 \pm 0.77$ & \\
\hline PIR & & & 0.248 \\
\hline$<1$ & $233(18.2 \%)$ & $0.23 \pm 0.97$ & \\
\hline$\geq 1$ & $910(71.0 \%)$ & $0.19 \pm 0.32$ & \\
\hline Education level & & & 0.228 \\
\hline Less than 9th grade & $156(12.2 \%)$ & $0.27 \pm 1.17$ & \\
\hline 9th-11th grade & $146(11.4 \%)$ & $0.17 \pm 0.25$ & \\
\hline High school graduate/GED or equivalent & $285(22.2 \%)$ & $0.20 \pm 0.44$ & \\
\hline Some college or AA degree & $364(28.4 \%)$ & $0.19 \pm 0.31$ & \\
\hline College graduate or above & $330(25.8 \%)$ & $0.18 \pm 0.20$ & \\
\hline
\end{tabular}

(Fig. 2). The relationship between blood cobalt and HOMA-IR in males and females is visualized by a scatter plot and fitted line with 95\% CI (Fig. 3). Figure 4 shows the continuous relationship of blood Co with HOMA-IR based on the restricted cubic spline regression models. Significant nonlinear associations were detected between blood Co and HOMA-IR among males $(P=0.037)$ and females $(P=0.023)$, although the overall population did not seem to show a significant difference.

Table 2 Multivariable associations of blood cobalt concentrations with insulin resistance in US adults during 2015-2016

\begin{tabular}{|c|c|c|c|c|c|c|c|}
\hline \multirow[t]{2}{*}{ HOMA-IR } & & \multicolumn{3}{|l|}{ Model 1} & \multicolumn{3}{|l|}{ Model 2} \\
\hline & & Coefficient & $95 \% \mathrm{Cl}$ & $P$ value & Coefficient & $95 \% \mathrm{Cl}$ & $P$ value \\
\hline \multirow[t]{3}{*}{ Continues variable } & Overall & -0.060 & $-0.142,0.023$ & 0.157 & -0.063 & $-0.137,0.011$ & 0.097 \\
\hline & Male & -0.032 & $-0.165,0.100$ & 0.631 & -0.082 & $-0.199,0.036$ & 0.173 \\
\hline & Female & -0.125 & $-0.234,-0.015$ & 0.026 & -0.095 & $-0.203,0.012$ & 0.082 \\
\hline
\end{tabular}

Model 1: age and gender

Model 2: model 1 plus race, BMI, PIR, alcohol use, and education level

Exposure variables and risk factor variables were log transformed in the models 
Table 3 Estimated coefficient (beta) and 95\% confidence intervals (95\% CI) of HOMA-IR in US adults during 2015-2016 for each quartile increase in blood cobalt levels stratified by different covariates

\begin{tabular}{|c|c|c|c|c|c|}
\hline HOMA-IR & Quartile 1 & Quartile 2 & Quartile 3 & Quartile 4 & $P$ for trend \\
\hline All & $0.038(-0.009,0.084)$ & $0.045(-0.004,0.094)$ & $0.03(-0.036,0.061)$ & Reference & 0.095 \\
\hline \multicolumn{6}{|l|}{ Age (years) } \\
\hline$<60$ & $0.073(0.007,0.139)$ & $0.056(-0.013,0.125)$ & $0.022(-0.048,0.093)$ & Reference & 0.016 \\
\hline$\geq 60$ & $-0.017(-0.083,0.049)$ & $0.030(-0.041,0.101)$ & $-0.006(-0.073,0.061)$ & Reference & 0.696 \\
\hline \multicolumn{6}{|l|}{ Gender } \\
\hline Male & $0.020(-0.056,0.096)$ & $0.032(-0.049,0.113)$ & $0.061(-0.024,0.146)$ & Reference & 0.732 \\
\hline Female & $0.062(0.001,0.123)$ & $0.061(-0.003,0.126)$ & $-0.016(-0.074,0.043)$ & Reference & 0.037 \\
\hline \multicolumn{6}{|l|}{ Ethnicity } \\
\hline Mexican American & $0.047(-0.063,0.158)$ & $-0.026(-0.143,0.091)$ & $-0.030(-0.145,0.086)$ & Reference & 0.779 \\
\hline Other Hispanic & $0.062(-0.064,0.188)$ & $0.082(-0.040,0.204)$ & $0.057(-0.071,0.185)$ & Reference & 0.853 \\
\hline Non-Hispanic White & $0.017(-0.053,0.087)$ & $0.050(-0.026,0.125)$ & $-0.005(-0.074,0.065)$ & Reference & 0.279 \\
\hline Non-Hispanic Black & $0.071(-0.050,0.192)$ & $0.083(-0.045,0.211)$ & $0.055(-0.087,0.198)$ & Reference & 0.146 \\
\hline Other race_-including multiracial & $0.049(-0.089,0.187)$ & $0.040(-0.110,0.191)$ & $0.021(-0.119,0.160)$ & Reference & 0.372 \\
\hline \multicolumn{6}{|l|}{ PIR } \\
\hline$<1$ & $-0.035(-0.145,0.075)$ & $-0.004(-0.119,0.112)$ & $-0.023(-0.127,0.082)$ & Reference & 0.452 \\
\hline$\geq 1$ & $0.055(0.004,0.106)$ & $0.057(0.003,0.112)$ & $0.020(-0.035,0.074)$ & Reference & 0.015 \\
\hline \multicolumn{6}{|l|}{ Alcohol use } \\
\hline Yes & $0.032(-0.024,0.089)$ & $0.064(0.003,0.124)$ & $0.038(-0.023,0.099)$ & Reference & 0.094 \\
\hline No & $0.076(-0.007,0.158)$ & $0.016(-0.068,0.101)$ & $-0.019(-0.099,0.061)$ & Reference & 0.382 \\
\hline \multicolumn{6}{|l|}{ BMI $\left(\mathrm{kg} / \mathrm{m}^{2}\right)$} \\
\hline$<25$ & $0.090(-0.003,0.183)$ & $0.080(-0.018,0.178)$ & $0.097(0.008,0.186)$ & Reference & 0.175 \\
\hline $25-30$ & $0.014(-0.058,0.085)$ & $0.063(-0.010,0.135)$ & $0.021(-0.053,0.095)$ & Reference & 0.177 \\
\hline$>30$ & $0.029(-0.049,0.107)$ & $0.011(-0.075,0.097)$ & $-0.059(-0.145,0.028)$ & Reference & 0.610 \\
\hline \multicolumn{6}{|l|}{ Education level } \\
\hline Less than 9th grade & $0.127(-0.004,0.257)$ & $0.041(-0.093,0.174)$ & $0.056(-0.074,0.186)$ & Reference & 0.205 \\
\hline 9th-11th grade & $0.102(-0.048,0.252)$ & $0.163(-0.001,0.326)$ & $0.129(-0.024,0.283)$ & Reference & 0.117 \\
\hline High school graduate/GED or equivalent & $0.041(-0.065,0.148)$ & $0.013(-0.094,0.120)$ & $0.029(-0.076,0.135)$ & Reference & 0.710 \\
\hline Some college or AA degree & $0.039(-0.046,0.123)$ & $0.073(-0.023,0.168)$ & $-0.006(-0.097,0.084)$ & Reference & 0.386 \\
\hline College graduate or above & $-0.019(-0.099,0.060)$ & $0.017(-0.067,0.101)$ & $-0.027(-0.116,0.061)$ & Reference & 0.718 \\
\hline
\end{tabular}

Model was adjusted for age, gender, race, BMI, PIR, alcohol use, and education level.

HOMA-IR homeostatic model assessment of insulin resistance, $B M I$ body mass index, PIR poverty index ratio

Cobalt $(\mu \mathrm{g} / \mathrm{L})$, quartile $1:<0.11$; quartile 2: $0.11-0.13$; quartile $3: 0.13-0.17$; quartile $4:>0.17$

\section{Discussion}

We were the first to observe significant negative correlations between blood cobalt levels and HOMA-IR in the general female adult population.

Few studies have focused on the associations of cobalt with IR and type 2 diabetes. The review by Dubey et al. summarized existing research on cobalt concentrations in diabetic patients; however, there is not enough research currently, and the existing research has produced inconsistent conclusions [20]. Cao et al. found that elevated or decreased plasma cobalt levels were associated with a high risk of type 2 diabetes [21]. Anjum et al. found that blood cobalt concentrations in diabetic patients were higher than those in non-diabetic patients [22]. The urinary and serum concentrations of cobalt were decreased in individuals with type 2 diabetes compared with those in non-diabetic participants [23]. However, Menke et al. reported that higher quartiles of urinary cobalt were not associated with IR [12] and type 2 diabetes risk [24]. A positive association between cobalt and beta cell function was also observed, but it was not statistically significant [25]. Our findings from a relatively large sample suggest that cobalt may play a potential role in the IR process. 


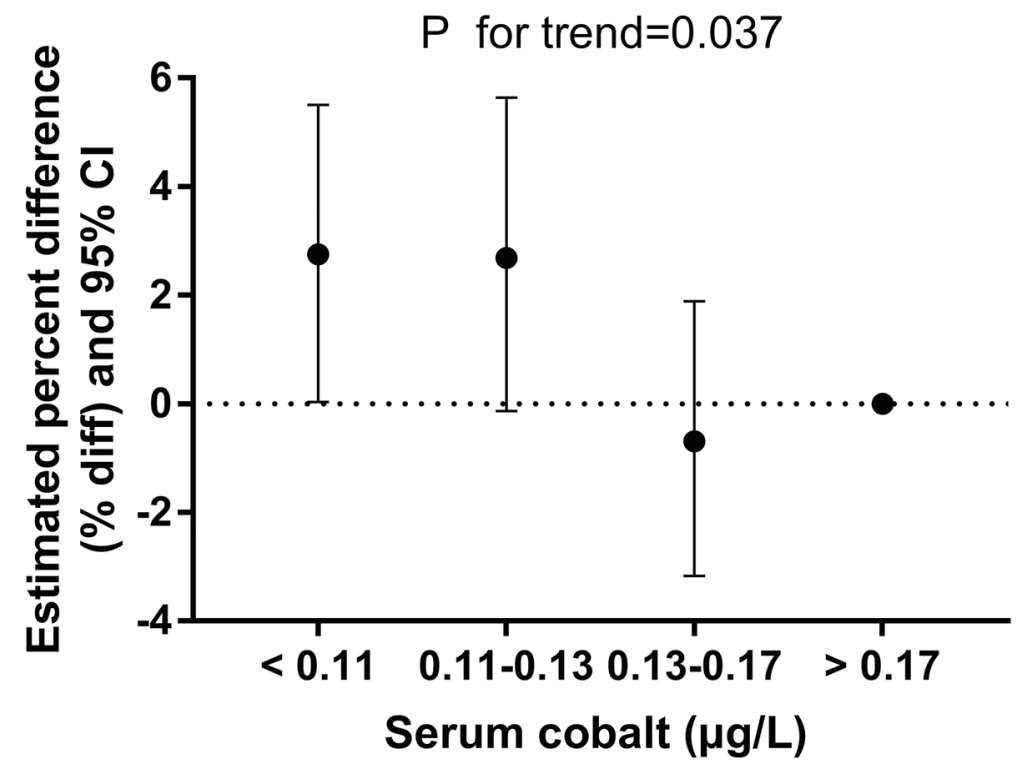

Fig. 2 Estimated percent difference (\% diff) and 95\% confidence intervals (95\% Cl) in HOMA-IR in US adults during 2015-2016 for each interquartile ratio (IQ ratio) increase in blood cobalt levels

Excess cobalt exposure, such as during the treatment of cell lines or mice with excessive cobalt chloride, may act as a hypoxia-mimetic agent that can inhibit adiponectin transcription, thus contributing to the development of IR in vitro [26] and in vivo [27]. Symptoms of cobalt deficiency include hypoxia, growth retardation, weight loss, hepatic steatosis, anemia, immune dysfunction, reproductive dysfunction, and even death [28]. Low-dose cobalt, as a trace element, has been shown to assemble into enzymes such as cobalt protoporphyrin and attenuate IR [29] and improve insulin sensitivity [30, 31 in mice. The median blood cobalt concentration was lower than that in a previous occupational population [32], suggesting that the general public is likely not exposed to the same type or amount of cobalt dust that caused these effects in workers. In addition, $23 \mu \mathrm{g} / \mathrm{L}$ and $53 \mu \mathrm{g} / \mathrm{L}$ of cobalt in whole blood in men and women, respectively, did not cause alterations in hearing, vision, and cardiac and neurological functions [33]. Thus, an appropriate dose of cobalt in the subjects may have exerted beneficial effects in the present study.

Our results revealed negative associations between cobalt and HOMA-IR, and we thus speculated that proper cobalt intake may benefit insulin sensitivity. Cobalt-protoporphyrin IX treatment can improve endothelial function and insulin sensitivity by reducing oxidative stress, restoring the balance of eNOS/iNOS expression, and increasing the $\mathrm{HO}-1$ level [34]. Another study showed that in the early stage of experimental diabetes, oral administration of $0.5 \mathrm{mM}$ cobalt in drinking water reduced increases in the levels of thiobarbituric acid reactive substances (TBARS) and antioxidant enzyme activities in the heart and aorta [35]. In addition, we found that the associations were significant in female adults but not in male adults. Tvermoes et al. found that female adults had higher rates of cobalt absorption and lower rates of cobalt excretion than male adults [33], which is consistent with our findings that the cobalt levels in female adults were higher than those in male adults. We speculate that the reason for the sex difference in our study is the higher iron demand in women. A common intestinal uptake mechanism is used for cobalt and iron absorption. Animal and human studies have indicated that iron deficiency may increase cobalt absorption [36-39].

The present study has several critical strengths. While previous epidemiological studies of cobaltrelated health effects were based on high exposure levels or small samples, the current study evaluated a relatively large sample with a nonoccupational cobalt exposure level. In addition to the common covariates, potential factors that may generate bias in the results, for example, PIR, alcohol use and education level, were included in our study. Furthermore, we performed separate analyses stratified by sex to explore whether cobalt 


\section{A}

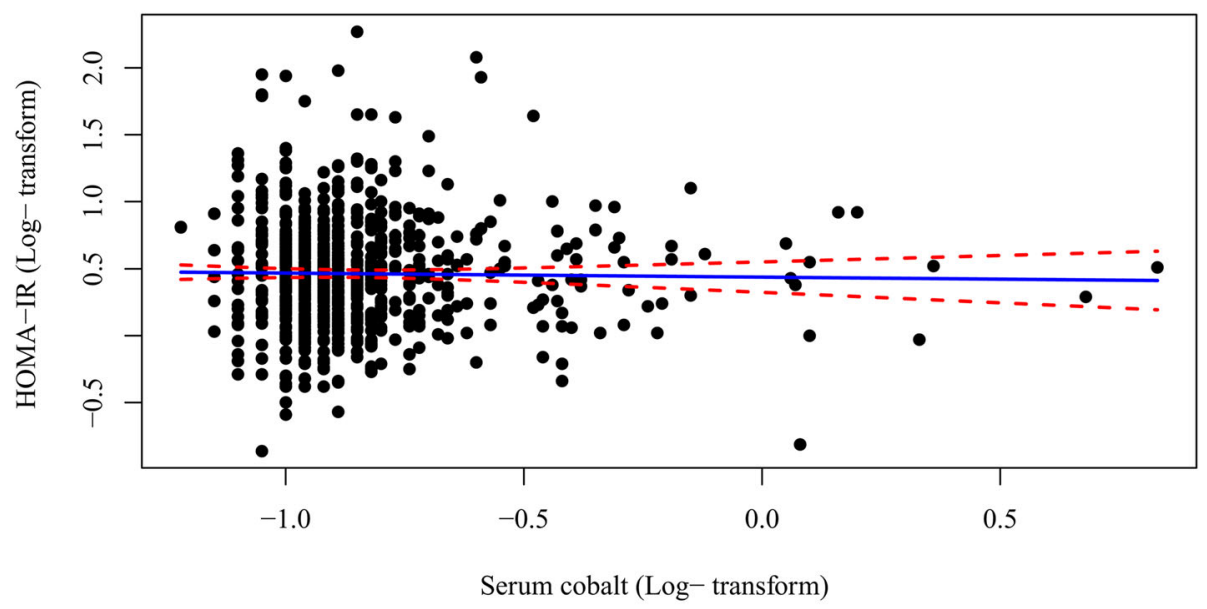

B

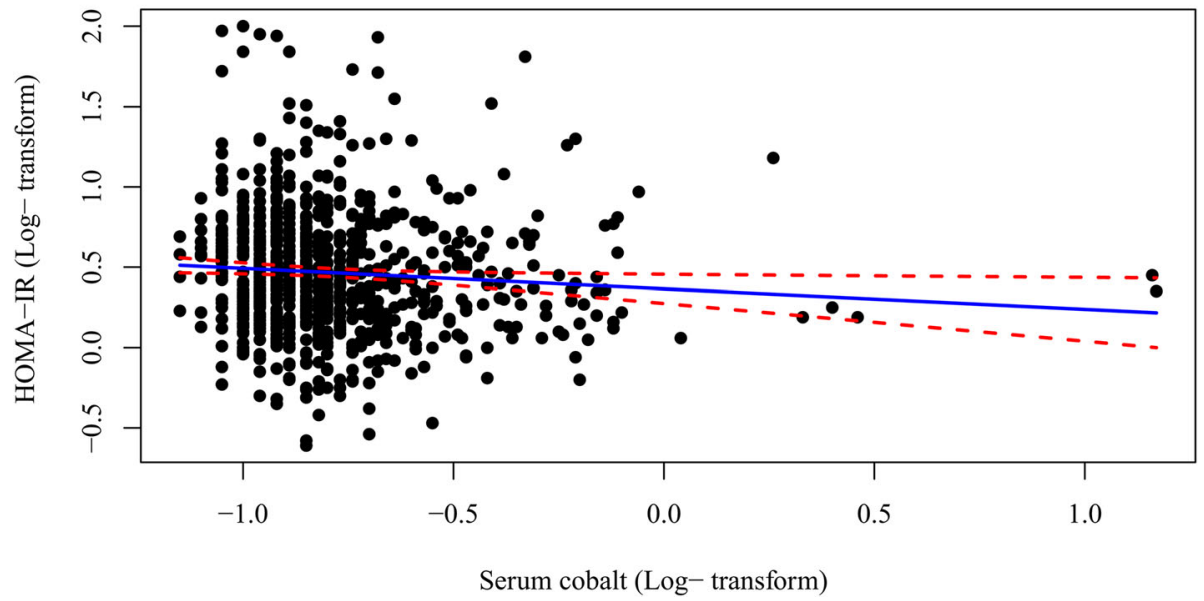

Fig. 3 A scatter plot and a fitted line with $95 \% \mathrm{Cl}$ showing the relationship between blood cobalt levels and HOMA-IR in male and female adults

has effects on the sensitivity of different groups. Some limitations were unavoidable in the current investigation. Due to the nature of cross-sectional studies, we cannot distinguish whether blood cobalt influences IR or vice versa. Moreover, many environmental chemicals (such as phthalates [40], polycyclic aromatic hydrocarbons [41], polyfluoroalkyl chemicals [42], and bisphenol A [43]) are potentially associated with IR. These chemicals were not assessed in our analysis, which may have impacts on the association between cobalt and IR. Future studies are necessary to evaluate the interaction effect of different environmental chemicals on the risk of IR. Additionally, some information, such as cobalt contained in multivitamins and the presence of polycystic ovarian syndrome and type 1 diabetes, was not collected in the NHANES, so these factors could not be excluded in our study. These factors may affect the results and conclusions.

\section{Conclusions}

In conclusion, the present study results indicated that blood cobalt exposure may be negatively associated with IR in the general US female adult population. Future research is needed to confirm this finding and investigate potential mechanisms. 

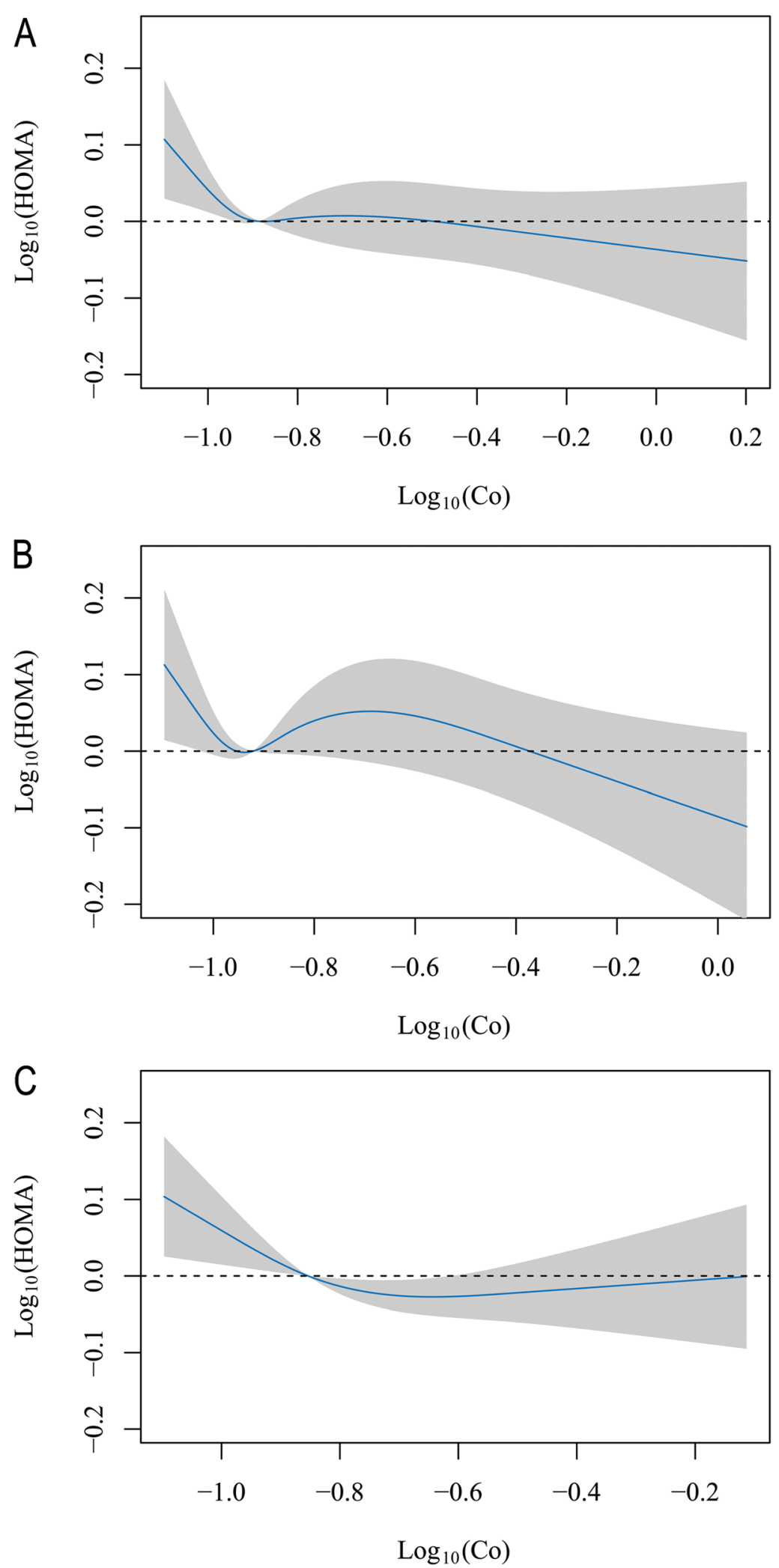

Fig. 4 Predicted spline curves for the associations of HOMA-IR with blood Co concentrations according to restricted cubic spline regression models in the overall population (a), in males (b) and in females (c) 


\section{Abbreviations}

IR: Insulin resistance; Cl: Confidence interval; HOMA-IR: Homeostatic model assessment of insulin resistance; NHANES: National Health and Nutrition Examination Survey; NCHS: National Center for Health Statistics; IQ: Interquartile

\section{Supplementary Information}

The online version contains supplementary material available at https://doi. org/10.1186/s12199-021-00966-w.

\section{Additional file 1.}

Additional file 2: Table 1. Insulin resistance indexes by quartile of cobalt concentration in US adults during 2015-2016.

Additional file 3: Table 2. Adjusted ORs ( $95 \% \mathrm{Cls}$ ) for the association between quartiles of blood cobalt concentration and HOMA-IR in all adults, stratified by gender.

\section{Acknowledgements}

Not applicable.

\section{Authors' contributions \\ Conceptualization, writing —original draft: Yong Chen and Xiaowei He. Formal analysis: Haobin Huang and Weiwei Duan. Methodology: Haobin Huang and Weiwei Duan. Data curation, writing - review and editing: All authors. The authors read and approved the final manuscript.}

\section{Funding}

This work was supported by funding from the National Science Foundation of China (81903409).

\section{Availability of data and materials}

All data generated or analyzed during this study are included in this published article and its supplementary information files.

\section{Declarations}

Ethics approval and consent to participate

Ethics approval was not required for this research.

\section{Consent for publication}

Not applicable.

\section{Competing interests}

The authors declare that they have no competing interests.

\section{Author details}

${ }^{1}$ Department of Cardiothoracic Surgery, Children's Hospital of Nanjing Medical University, 72 Guangzhou Road, Nanjing 210008, China. ${ }^{2}$ Department of Cardiovascular Surgery, the First Affiliated Hospital, Nanjing Medical University, Nanjing 210029, Jiangsu Province, China. ${ }^{3}$ Department of Endocrinology and Metabolism/Diabetes Care and Research Center, Nanjing Medical University Affiliated Geriatric Hospital/Jiangsu Province Geriatric Hospital, Jiangsu Province Official Hospital/Jiangsu Province Institute of Geriatrics, Nanjing, China. ${ }^{4}$ Department of Bioinformatics, School of Biomedical Engineering and Informatics, Nanjing Medical University, 101 Longmian Avenue, Nanjing 211166, China.

Received: 21 January 2021 Accepted: 17 March 2021 Published online: 27 March 2021

\section{References}

1. Kahn CR. Insulin resistance, insulin insensitivity, and insulin unresponsiveness: a necessary distinction. Metabolism. 1978;27(12):1893902. https://doi.org/10.1016/50026-0495(78)80007-9.

2. Zick $Y$. Insulin resistance: a phosphorylation-based uncoupling of insulin signaling. Trends Cell Biol. 2001;11(11):437-41. https://doi.org/10.1016/ S0962-8924(01)02129-8.
3. Moghetti P. Insulin resistance and polycystic ovary syndrome. Curr Pharm Des. 2016;22(36):5526-34. https://doi.org/10.2174/13816128226661607201 55855.

4. De Felice FG, Lourenco MV, Ferreira ST. How does brain insulin resistance develop in Alzheimer's disease? Alzheimers Dement. 2014;10(1 Suppl):S2632. https://doi.org/10.1016/j.jalz.2013.12.004.

5. Ma L, Wang J, Li Y. Insulin resistance and cognitive dysfunction. Clin Chim Acta. 2015;444:18-23. https://doi.org/10.1016/j.cca.2015.01.027.

6. Brown $A E$, Walker $M$. Genetics of insulin resistance and the metabolic syndrome. Curr Cardiol Rep. 2016;18(8):75. https://doi.org/10.1007/s11886-01 6-0755-4

7. Kahn SE, Hull RL, Utzschneider KM. Mechanisms linking obesity to insulin resistance and type 2 diabetes. Nature. 2006:444(7121):840-6. https://doi. org/10.1038/nature05482.

8. Caricilli AM, Saad MJ. Gut microbiota composition and its effects on obesity and insulin resistance. Curr Opin Clin Nutr Metab Care. 2014;17(4):312-8. https://doi.org/10.1097/MCO.0000000000000067.

9. Gratas-Delamarche A, Derbre F, Vincent S, Cillard J. Physical inactivity, insulin resistance, and the oxidative-inflammatory loop. Free Radic Res. 2014;48(1): 93-108. https://doi.org/10.3109/10715762.2013.847528.

10. Kelishadi R, Mirghaffari N, Poursafa P, Gidding SS. Lifestyle and environmental factors associated with inflammation, oxidative stress and insulin resistance in children. Atherosclerosis. 2009;203(1):311-9. https://doi. org/10.1016/j.atherosclerosis.2008.06.022.

11. Hectors TL, Vanparys C, Van Gaal LF, Jorens PG, Covaci A, Blust R. Insulin resistance and environmental pollutants: experimental evidence and future perspectives. Environ Health Perspect. 2013;121(11-12):1273-81. https://doi. org/10.1289/ehp.1307082.

12. Menke A, Guallar E, Cowie CC. Metals in urine and diabetes in U.S. adults. Diabetes. 2016;65:164-71. https://doi.org/10.2337/db15-0316.

13. Rizzo G, Lagana AS, Rapisarda AM, La Ferrera GM, Buscema M, Rossetti P, et al. Vitamin B12 among vegetarians: status, assessment and supplementation. Nutrients. 2016;8(12). https://doi.org/10.3390/nu8120767.

14. Czarnek K, Terpilowska S, Siwicki AK. Selected aspects of the action of cobalt ions in the human body. Cent Eur J Immunol. 2015;40(2):236-42. https://doi. org/10.5114/ceji.2015.52837.

15. Lauwerys RRHP. Cobalt in industrial chemical exposure: guidelines for biological monitoring. 3rd ed. Boca Raton: Lewis Publishers Biological monitoring of exposure to inorganic and oranometallic substances; 2001. https://doi.org/10.1201/9781482293838

16. CDC. Centers for Disease Control and Prevention. National Center for Health Statistics. National Health and Nutrition Examination Survey. Chromium and cobalt in whole blood. Laboratory Procedure Manual. Available at: https:// wwwn.cdc.gov/nchs/data/nhanes/2015-2016/labmethods/CRCO_I_MET_ Chromium\%20and\%20Cobalt.pdf.

17. Prevention CfDCa. National Center for Health Statistics. National Health and Nutrition Examination Survey. Plasma Fasting Glucose. Laboratory Procedure Manual. Available at: https://wwwn.cdc.gov/nchs/data/nhanes/2015-2016/la bmethods/GLU I MET.pdf.

18. Matthews DR, Hosker JP, Rudenski AS, Naylor BA, Treacher DF, Turner RC. Homeostasis model assessment: insulin resistance and beta-cell function from fasting plasma glucose and insulin concentrations in man. Diabetologia. 1985:28(7):412-9. https://doi.org/10.1007/BF00280883.

19. Demmer RT, Squillaro A, Papapanou PN, Rosenbaum M, Friedewald WT, Jacobs DR Jr, et al. Periodontal infection, systemic inflammation, and insulin resistance: results from the continuous National Health and Nutrition Examination Survey (NHANES) 1999-2004. Diabetes Care. 2012;35(11):223542. https://doi.org/10.2337/dc12-0072

20. Dubey $P$, Thakur $V$, Chattopadhyay M. Role of minerals and trace elements in diabetes and insulin resistance. Nutrients. 2020;12(6). https//doi.org/10.3390/nu12061864.

21. Cao B, Fang C, Peng X, Li X, Hu X, Xiang P, et al. U-shaped association between plasma cobalt levels and type 2 diabetes. Chemosphere. 2021;267: 129224. https://doi.org/10.1016/j.chemosphere.2020.129224.

22. Anbreen Anjum MY. Mohammad Zuber, Hafiz Badar. Comparative study on calcium, magnesium and cobalt in diabetic and non diabetic patients (males) in Punjab, Pakistan. Afr J Biotechnol. 2012;28:7258-62.

23. Flores CR, Puga MP, Wrobel K, Garay Sevilla ME, Wrobel K. Trace elements status in diabetes mellitus type 2: possible role of the interaction between molybdenum and copper in the progress of typical complications. Diabetes Res Clin Pract. 2011;91(3):333-41. https:// doi.org/10.1016/j.diabres.2010.12.014 
24. Feng W, Cui X, Liu B, Liu C, Xiao Y, Lu W, et al. Association of urinary metal profiles with altered glucose levels and diabetes risk: a population-based study in China. PLoS One. 2015;10(4):e0123742. https://doi.org/10.1371/ journal.pone.0123742.

25. Wang X, Mukherjee B, Karvonen-Gutierrez CA, Herman WH, Batterman S, Harlow SD, et al. Urinary metal mixtures and longitudinal changes in glucose homeostasis: The Study of Women's Health Across the Nation (SWAN). Environ Int. 2020;145:106109. https://doi.org/10.1016/j.envint.2020.1 06109.

26. Regazzetti C, Peraldi P, Gremeaux T, Najem-Lendom R, Ben-Sahra I, Cormont $M$, et al. Hypoxia decreases insulin signaling pathways in adipocytes. Diabetes. 2009;58(1):95-103. https://doi.org/10.2337/db08-0457.

27. Zappala G, Rechler MM. IGFBP-3, hypoxia and TNF-alpha inhibit adiponectin transcription. Biochem Biophys Res Commun. 2009;382(4):785-9. https://doi. org/10.1016/j.bbrc.2009.03.112.

28. Gonzalez-Montana JR, Escalera-Valente F, Alonso AJ, Lomillos JM, Robles R, Alonso ME. Relationship between Vitamin B12 and Cobalt Metabolism in Domestic Ruminant: An Update. Animals. 2020;10(10). https://doi.org/10.33 90/ani10101855

29. Burgess A, Li M, Vanella L, Kim DH, Rezzani R, Rodella L, et al. Adipocyte heme oxygenase-1 induction attenuates metabolic syndrome in both male and female obese mice. Hypertension. 2010;56(6):1124-30. https://doi.org/1 0.1161/HYPERTENSIONAHA.110.151423.

30. Li M, Kim DH, Tsenovoy PL, Peterson SJ, Rezzani R, Rodella LF, et al. Treatment of obese diabetic mice with a heme oxygenase inducer reduces visceral and subcutaneous adiposity, increases adiponectin levels, and improves insulin sensitivity and glucose tolerance. Diabetes. 2008;57(6): 1526-35. https://doi.org/10.2337/db07-1764.

31. Liu X, Gao Y, Li M, Geng C, Xu H, Yang Y, et al. Sirt1 mediates the effect of the heme oxygenase inducer, cobalt protoporphyrin, on ameliorating liver metabolic damage caused by a high-fat diet. J Hepatol. 2015;63(3):713-21. https://doi.org/10.1016/j.jhep.2015.05.018.

32. Lantin AC, Mallants A, Vermeulen J, Speybroeck N, Hoet P, Lison D. Absence of adverse effect on thyroid function and red blood cells in a population of workers exposed to cobalt compounds. Toxicol Lett. 2011;201(1):42-6. https://doi.org/10.1016/j.toxlet.2010.12.003.

33. Tvermoes BE, Unice KM, Paustenbach DJ, Finley BL, Otani JM, Galbraith DA. Effects and blood concentrations of cobalt after ingestion of $1 \mathrm{mg} / \mathrm{d}$ by human volunteers for 90 d. Am J Clin Nutr. 2014;99(3):632-46. https://doi. org/10.3945/ajcn.113.071449.

34. Cao J, Vecoli C, Neglia D, Tavazzi B, Lazzarino G, Novelli M, et al. Cobaltprotoporphyrin improves heart function by blunting oxidative stress and restoring $\mathrm{NO}$ synthase equilibrium in an animal model of experimental diabetes. Front Physiol. 2012;3:160. https://doi.org/10.3389/fphys.2012.00160.

35. Yildirim $\mathrm{O}$, Buyukbingol Z. Effect of cobalt on the oxidative status in heart and aorta of streptozotocin-induced diabetic rats. Cell Biochem Funct. 2003; 21(1):27-33. https://doi.org/10.1002/cbf.995.

36. Valberg LS, Ludwig J, Olatunbosun D. Alteration in cobalt absorption in patients with disorders of iron metabolism. Gastroenterology. 1969;56(2): 241-51. https://doi.org/10.1016/S0016-5085(69)80123-X.

37. Meltzer HM, Brantsaeter AL, Borch-lohnsen B, Ellingsen DG, Alexander J, Thomassen $Y$, et al. Low iron stores are related to higher blood concentrations of manganese, cobalt and cadmium in non-smoking, Norwegian women in the HUNT 2 study. Environ Res. 2010;110(5):497-504 https://doi.org/10.1016/j.envres.2010.03.006.

38. Reuber $S$, Kreuzer M, Kirchgessner $M$. Interactions of cobalt and iron in absorption and retention. J Trace Elem Electrolytes Health Dis. 1994;8(3-4): 151-8.

39. Thomson AB, Valberg LS. Intestinal uptake of iron, cobalt, and manganese in the iron-deficient rat. Am J Physiol. 1972;223(6):1327-9. https://doi.org/1 0.1152/ajplegacy.1972.223.6.1327.

40. Trasande L, Spanier AJ, Sathyanarayana S, Attina TM, Blustein J. Urinary phthalates and increased insulin resistance in adolescents. Pediatrics. 2013; 132(3):e646-55. https://doi.org/10.1542/peds.2012-4022.

41. Hu H, Kan H, Kearney GD, Xu X. Associations between exposure to polycyclic aromatic hydrocarbons and glucose homeostasis as well as metabolic syndrome in nondiabetic adults. Sci Total Environ. 2015;505:5664. https://doi.org/10.1016/j.scitotenv.2014.09.085.

42. Nelson JW, Hatch EE, Webster TF. Exposure to polyfluoroalkyl chemicals and cholesterol, body weight, and insulin resistance in the general U.S. population. Environ Health Perspect. 2010;118(2):197-202. https://doi.org/1 0.1289/ehp.0901165.

43. Savastano S, Tarantino G, D'Esposito V, Passaretti F, Cabaro S, Liotti A, et al. Bisphenol-A plasma levels are related to inflammatory markers, visceral obesity and insulin-resistance: a cross-sectional study on adult male population. J Transl Med. 2015;13(1):169. https://doi.org/10.1186/s12967-0150532-y.

\section{Publisher's Note}

Springer Nature remains neutral with regard to jurisdictional claims in published maps and institutional affiliations.
Ready to submit your research? Choose BMC and benefit from:

- fast, convenient online submission

- thorough peer review by experienced researchers in your field

- rapid publication on acceptance

- support for research data, including large and complex data types

- gold Open Access which fosters wider collaboration and increased citations

- maximum visibility for your research: over $100 \mathrm{M}$ website views per year

At BMC, research is always in progress.

Learn more biomedcentral.com/submissions 